\title{
Expression of an $\alpha$-Galactosidase Gene in Petunia is Upregulated during Low-temperature Deacclimation
}

\author{
Joyce C. Pennycooke', Ramarao Vepachedu, and Cecil Stushnoff \\ Department of Horticulture and Landscape Architecture, Colorado State University, Fort Collins, \\ CO 80523 \\ Michelle L. Jones ${ }^{2}$ \\ Department of Horticulture and Crop Science, The Ohio State University/OARDC, Wooster, OH 44691
}

ADDITIONAL INDEX WORDS. chilling injury, cold acclimation, cloning, freezing tolerance, raffinose catabolism

\begin{abstract}
Previous studies of plant tolerance to low temperature have focused primarily on the cold acclimation response, the process by which plants increase their tolerance to freezing in response to low nonfreezing temperatures, while studies on the deacclimation process have been largely neglected. In some plants, cold acclimation is accompanied by an increase in raffinose family oligosaccharides (RFO). The enzyme $\alpha$-galactosidase (EC 3.2.1.22) breaks down RFO during deacclimation by hydrolyzing the terminal galactose moieties. Here we describe the isolation of PhGAL, an $\alpha$-galactosidase

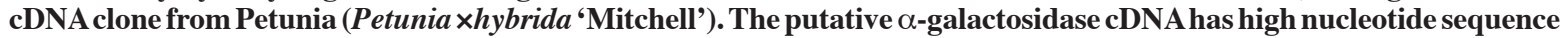
homology $(>80 \%)$ to other known plant $\alpha$-galactosidases. PhGAL expression increased in response to increased temperature and there was no evidence of developmental regulation or tissue specific expression. Increases in $\alpha$-galactosidase transcript 1 hour into deacclimation corresponded with increases in $\alpha$-galactosidase activity and a concomitant decrease in raffinose content, suggesting that warm temperature may regulate RFO catabolism by increasing the transcription of the $\alpha$-galactosidase gene. This information has potential practical applications whereby $\alpha$-galactosidase may be targeted to modify endogenous raffinose accumulation in tissues needed for freezing stress tolerance.
\end{abstract}

Late spring and early fall frosts can cause substantial damage to bedding plants like petunia because they are less cold tolerant and lack rapid acclimation response mechanisms found in other species, including Brassicas and spinach. Plants capable of cold acclimation require a growth period or incubation at low nonfreezing temperature to trigger the appropriate genes needed for subsequent cold tolerance. During this period of cold acclimation, biochemical pathways, physiological processes, and gene expression are altered in plants (Guy, 1990). Previous biochemical and physiological studies have demonstrated the accumulation of specific metabolites such as the raffinose family oligosaccharides (RFO) upon low temperature exposure (Bachmann et al., 1994). Raffinose accumulation in pansies increased during low-temperature-induced cold acclimation (Stushnoff et al., 1998). Furthermore, wild-type Arabidopsis plants increased accumulation of raffinose and galactinol synthase upon cold acclimation (Taji et al., 2002). One of the suggested functions of these metabolites is membrane protection upon low-temperature stress. In spite of ample evidence demonstrating a significant shift in carbohydrate status of plants at low temperature, very few studies of the enzymes involved in carbohydrate biosynthesis and even fewer on RFO catabolism have been undertaken. Castonguay and Nadeau (1998) showed that $\alpha$-galactosidase ( $\alpha$-gal) (EC 3.2.1.22), the key enzyme involved in the breakdown of RFO, increased activity during spring dehardening at the time when RFO levels decreased rapidly.

Received for publication 28 Aug. 2003. Accepted for publication 10 Dec. 2003. Salaries and research support provided in part by state and federal funds appropriated to the Ohio Agricultural Research and Development Center, The Ohio State University. Manuscript HCS03-18.

${ }^{1}$ Current address: Department of Horticulture and Crop Science, The Ohio State University/OARDC, Wooster, OH 44691.

2Corresponding author; email jones.1968@osu.edu.
$\alpha$-Galactosidase is widely distributed in microorganisms, humans, and plants, and cDNAs have been cloned from several sources including human (Bishop et al., 1986), soybean (Davis et al., 1996), tomato seed (Feurtado et al., 2001), yeast (Liljestrom, 1985), guar (Overbeeke et al., 1989), and coffee bean (Zhu and Goldstein, 1994). The isolation of $\alpha$-gal clones from the abovementioned sources demonstrated the diverse role of this enzyme in seed germination, assimilate partitioning, and seroconversion of blood group $\mathrm{B}$ to $\mathrm{O}$.

Multiple forms of the $\alpha$-gal enzyme have been described (Keller and Pharr, 1996). These can be divided into two groups, acid and alkaline, based on their activity response to $\mathrm{pH}$. Most studies have dealt with the acid forms of the enzyme, which play important roles in seed germination (Keller and Pharr, 1996). In the Cucurbits, Gaudreault and Webb (1986) described an alkaline $\alpha$-gal from young leaves of Cucurbita pepo, in addition to multiple acid forms of the enzyme. The alkaline forms were unique in that they showed high affinity for stachyose and little activity toward raffinose compared with the acid forms, for which raffinose was found to be the preferred substrate (Gaudreault and Webb, 1996). However, Gao and Schaffer (1999) later reported a novel alkaline $\alpha$-gal from melon fruit, which can hydrolyze both raffinose and stachyose. Recently, two alkaline $\alpha$-gals from melon fruit were cloned showing high nucleotide homology to seed imbibition proteins (SIPs) and little homology with eukaryotic and prokaryotic $\alpha$-gals of families 27 and 36 of the glycosyl hydrolases (Cami et al., 2003).

A combined molecular and physiological approach to investigate the relationship between the expression of $\alpha$-gal and loss of cold tolerance in petunia is important as the prediction of loss of hardiness is a critical issue for growers. The objectives of this study were to identify and clone $\alpha$-gal gene(s) in petunia, determine if any putative $\alpha$-gal(s) were expressed in response to deacclimating conditions, and to find out how this relates to loss of hardiness. 


\section{Materials and Methods}

Plant materials and treatments. Petunia $\times$ hybrida 'Mitchell' plants were grown from seed and maintained in a greenhouse at $22{ }^{\circ} \mathrm{C}$ with a $16 / 8$-h photoperiod. Supplemental lighting was provided during the winter by lamps (430-W; Agro Sun, Denver). Eight-week-old plants were transferred to a growth chamber to induce cold acclimation by incubating at $15^{\circ} \mathrm{C}$ for $7 \mathrm{~d}, 10$ ${ }^{\circ} \mathrm{C}$ for $7 \mathrm{~d}, 5^{\circ} \mathrm{C}$ for $7 \mathrm{~d}$, and subsequently at $3{ }^{\circ} \mathrm{C}$ for $3 \mathrm{~d}$ with a 12/12-h photoperiod under cool-white fluorescent light at 60 $\mu \mathrm{mol} \cdot \mathrm{m}^{-2} \cdot \mathrm{s}^{-1}$. Plants were deacclimated by incubating previously cold-acclimated plants at $25^{\circ} \mathrm{C}$ with a $16 / 8$-h photoperiod under cool-white fluorescent light at $60 \mu \mathrm{mol} \cdot \mathrm{m}^{-2} \cdot \mathrm{s}^{-1}$ for varying periods of time. In a separate experiment, plants were deacclimated for $1 \mathrm{~h}$ at various temperatures $\left(25\right.$ to $\left.40{ }^{\circ} \mathrm{C}\right)$.

Acclimation to low temperature and deacclimation in response to high temperature were monitored by evaluating susceptibility to chilling injury (CI). CI stress tests were conducted on cold acclimated and deacclimated plants by incubating at $2{ }^{\circ} \mathrm{C}$ for 1 $\mathrm{h}$ in light. Chilled plants were left at room temperature for one day and sampled to determine electrolyte leakage as a measure of membrane damage. To determine electrolyte leakage, leaf discs (5 $\mathrm{mm}$ in diameter) were immersed in individual cells of a leakage tray of a 100-well seed analyzer (ASAC; Neogen, East Lansing, Mich.) containing $2 \mathrm{~mL}$ of deionized water, previously tested to read 0 conductivity. After the conductivity of the solution was measured $\left(\mathrm{T}_{1}\right)$, the leaf discs were frozen at $-80^{\circ} \mathrm{C}$ overnight, and thawed at room temperature $\left(22^{\circ} \mathrm{C}\right)$ to destroy compartmentalization so total potential leakage $\left(\mathrm{T}_{2}\right)$ could be determined. Relative percent injury represents the mean leakage as a percentage of the mean total leakage from frozen-killed samples $\left(T_{1} / T_{2} \times 100\right)$.

Tissue samples for northern blots included roots, stems, and flowers, as well as leaves at different developmental stages. For developmental regulation of $\alpha$-gal, 10 randomly selected seedlings were used and the first eight true leaves were numbered according to their order of appearance. Leaf area measurements of the expanding leaves were recorded weekly, at 10:00 Am each time. The leaf relative expansion rate was determined as a function of developmental stage.

ISOLATION, CLONING, AND SEQUENCING OF $\alpha$-GALACTOSIDASE. A putative $\alpha$-gal cDNA was isolated from petunia total RNA using the Access RT-PCR System according to the manufacturer's recommendations (Promega, Madison, Wis.). Total RNA was obtained from leaves of 8-week-old deacclimated petunia plants using the TRIZOL reagent according to the manufacturer's recommendations (Gibco; BRL, Rockville, Md.). Degenerate primers Gal5' (5' ATGGGRTGGARYAGCTGGAAYCA $3^{\prime}$ ) and Gal3' (5' CTDARWGGHCCDGCCCAWACCTC $3^{\prime}$ ) were designed based on other plant $\alpha$-gal sequences. RT-PCR reactions were carried out in a volume of $50 \mu \mathrm{L}$ containing (final concentration) $1 \times \mathrm{AMV}$ $\mathrm{T} f$ Reaction Buffer, $0.2 \mathrm{~mm}$ dNTP mix, $5 \mu \mathrm{m}$ of each primer, 1 mM $\mathrm{MgSO}_{4}, 0.1 \mathrm{U} / \mu \mathrm{L}$ AMV RT, $0.1 \mathrm{U} / \mu \mathrm{L} \mathrm{T} f$ DNA polymerase, and $1 \mu \mathrm{g}$ total RNA. Cycling was performed in a thermocycler (Mastercycler; Eppendorf, Westbury, N.Y.) under the following conditions: reverse transcription at $48{ }^{\circ} \mathrm{C}$ for $45 \mathrm{~min}$, AMV RT inactivation and RNA/cDNA/primer denaturation at $94{ }^{\circ} \mathrm{C}$ for 2 min followed by 40 cycles of denaturation at $94^{\circ} \mathrm{C}$ for $1 \mathrm{~min}$, annealing at $65^{\circ} \mathrm{C}$ for $1.5 \mathrm{~min}$, and extension at $72{ }^{\circ} \mathrm{C}$ for $2 \mathrm{~min}$ followed by a final extension at $72{ }^{\circ} \mathrm{C}$ for $7 \mathrm{~min}$. The amplified product was purified and cloned into the pCR 2.1-TOPO expression vector (Invitrogen, Carlsbad, Calif.). The putative clone designated PhGAL was sequenced using a DNA sequencer (Perkin Elmer 377;
ABI Prism, v.3.2) by the Dept. of Biochemistry and Molecular Biology at Colorado State Univ., Fort Collins.

Sequence analyses and amino aCid alignment. Sequence analyses were performed using the Basic Local Alignment Search Technique (BLAST) via the National Center for Biotechnology Information (NCBI) database (Altschul et al., 1997). The deduced $P h G A L$ protein sequence was aligned with other known $\alpha$-gal sequences in the database using the Vector NTI Suite software (InforMax, Bethesda, Md.).

$\alpha$-GalaCtOSIDASE EXTRACTION AND ACTIVITY ASSAY. The eXtraction of $\alpha$-gal was performed as described by Smart and Pharr (1980). The resulting $\alpha$-gal was assayed using $p$-nitrophenyl$\alpha$-D-galactopyranoside (PNPG). Assay mixtures contained 100 $\mu \mathrm{L}$ of enzyme extract in $400 \mu \mathrm{L}$ of McIlvaine buffer ( $\mathrm{pH}$ 6.0) (Mcllvaine, 1921) at $30{ }^{\circ} \mathrm{C}$. The reaction was started by adding $100 \mu \mathrm{L}$ of $30 \mathrm{~mm}$ PNPG and terminated after 20 min by adding $2.4 \mathrm{~mL}$ of $5 \% \mathrm{Na}_{2} \mathrm{CO}_{3}$. Blanks were prepared by adding enzyme after $\mathrm{Na}_{2} \mathrm{CO}_{3}$. Absorbance was read at $400 \mathrm{~nm}$ and for quantifying enzyme activity, the amount of $p$-nitrophenol released was calculated using a molar extinction coefficient of $1.83 \times 10^{4}$ $\mathrm{M}^{\cdot} \mathrm{cm}^{-1}$. One unit of enzyme activity was defined as $1 \mu \mathrm{mol}$ of PNPG hydrolyzed per minute. Total protein was estimated by the Lowry method using bovine serum albumin (BSA) as the standard (Lowry et al., 1951).

RAFFinose ANALYSIS. For raffinose analyses, leaf tissues were sampled $2 \mathrm{~h}$ into the photoperiod from all stages of leaf development at the same time samples were collected for enzyme activity and RNA extraction. Samples from each plant were pooled together and immediately drenched in liquid nitrogen. Total soluble sugars were extracted from lyophilized leaf tissue $(5 \mathrm{mg})$ in $5 \mathrm{~mL} 80 \%$ (v/v) ethanol at $90{ }^{\circ} \mathrm{C}$ for $20 \mathrm{~min}$. Samples were centrifuged at $100 g_{\mathrm{n}}$ for $2 \mathrm{~min}$ and the supernatant was collected. A total of three rounds of the hot ethanol and centrifugation steps was performed. The supernatants of these samples were pooled and evaporated to dryness under nitrogen gas overnight at room temperature. The samples were resuspended in $5 \mathrm{~mL}$ deionized water and filtered through a $0.22-\mu \mathrm{m}$ filter membrane. Extracts were analyzed by high-performance liquid chromatography (Dionex, Sunnyvale, Calif.) equipped with a CarboPac PA 10 column and pulsed amperometric detection (PAD) system.

RNAEXTRACTION AND NORTHERN BLOT ANALYSIS. Samples were collected from leaves of 8 -week-old acclimated and deacclimated plants at various temperatures and time points and from flowers, leaves, stems and roots. To determine if $\alpha$-gal is developmentally regulated, samples were collected from the first eight true leaves of 8-week-old plants. Leaves were sorted into four groups: $1^{\text {st }}$ to $2^{\text {nd }}, 3^{\text {rd }}$ to $4^{\text {th }}, 5^{\text {th }}$ to $6^{\text {th }}$, and $7^{\text {th }}$ to $8^{\text {th }}$, according to their appearance order. Leaf relative expansion rate as determined by weekly area measurements was used as a function of developmental stage. Samples were frozen in liquid nitrogen and stored at $-80{ }^{\circ} \mathrm{C}$ until used for RNA extraction as described for RT-PCR. RNA was quantified spectrophotometrically and $10 \mu \mathrm{g}$ of total RNA was separated by electrophoresis through a $1 \%(\mathrm{w} / \mathrm{v})$ agarose gel containing 2.2 м formaldehyde. Equal loading of RNA samples was confirmed by visual observation of the RNA gel following staining with ethidium bromide. The separated RNAs were transferred to Nytran membranes (Schleicher \& Schuell, Keene, N.H.) and cross-linked with a controlled UV light source (Stratalinker; Stratagene, LaJolla, Calif.). After air-drying at room temperature, the membranes were prehybridized in $20 \mathrm{~mL}$ prewarmed solution [50\% formamide, $5 \times$ SSPE, $1 \times$ Denhardt's (1966) solution, $0.1 \%$ SDS, $10 \mathrm{mg} \cdot \mathrm{mL}^{-1}$ denatured salmon sperm DNA] for $2.5 \mathrm{~h}$ at 43 
1 atgggnggaagaagcggaatcctttttggttgctatattgacgag $\begin{array}{lllllllllllllll}M & G & G & R & S & G & I & L & F & G & C & Y & I & D & E\end{array}$

46 aaatgataagggaaacagctgatgcaatggtatacactgggctt $\begin{array}{lllllllllllllll}K & M & I & R & E & T & A & D & A & M & V & Y & T & G & I\end{array}$

91 tcttctcttggatacaaatacatcaatcttgatgactgttgggct $\begin{array}{lllllllllllllll}S & S & I & G & Y & K & Y & I & N & I & D & D & C & W & A\end{array}$

136 gaactcaacagggactctcaggggaatatggttcctaaaggttca $\begin{array}{lllllllllllllll}E & L & N & R & D & S & Q & G & N & M & V & P & K & G & S\end{array}$

181 actttccttctggaattaaagcactagcagattatgttcacaac $\begin{array}{lllllllllllllll}T & F & P & S & G & I & K & A & \text { L } & A & D & Y & V & H & N\end{array}$

226 aaggattgaacctcggaatttattctgatgctgggactcaaacg $\begin{array}{lllllllllllllll}K & G & L & N & L & G & I & Y & S & D & A & G & T & Q & T\end{array}$

271 tgtagtaaagaatgccaggttcattaggtcacgaagaacaagat $\begin{array}{lllllllllllllll}C & S & K & E & M & P & G & S & L & G & H & E & E & Q & D\end{array}$

316 gcaaaactttgcttcctggggagttgattacttgaagtatgat $\begin{array}{lllllllllllllll}A & K & T & F & A & S & W & G & V & D & Y & L & K & Y & D\end{array}$

361 aactgtaacaatgaaatcgaagtccaagagaaaggtatcctaca $\begin{array}{lllllllllllllll}N & C & N & N & E & N & R & S & P & R & E & R & Y & P & T\end{array}$

406 atgagcaaagctctacaaactctggaagggctatatttattcc $\begin{array}{lllllllllllllll}M & S & K & A & L & Q & N & S & G & R & A & I & F & Y & S\end{array}$

451 ctatgtgaatggggagatgatgatcctgccacttgggctttctct $\begin{array}{lllllllllllllll}L & C & E & W & G & D & D & D & P & A & T & W & A & F & S\end{array}$

496 gttggaaatagttggagaactactggagatatttctgataactgg $\begin{array}{lllllllllllllllllllllllllll}V & G & N & S & W & R & T & T & G & D & I & S & D & N & W\end{array}$

541 gacagtatgacatctcgggcggatcaaatgataaatgggcatct $\begin{array}{llllllllllllllll}D & S & M & T & S & R & A & D & Q & N & D & K & W & A & S\end{array}$

586 tatgctggtccaggaggctggaatgatccagacatgttagaagtt $\begin{array}{lllllllllllllll}Y & A & G & P & G & G & W & N & D & P & D & M & L & E & V\end{array}$

631 ggaatggaggaatgacaactgcagaatatcgttcacatttcagc $\begin{array}{lllllllllllllll}G & N & G & G & M & T & T & A & E & Y & R & S & H & F & S\end{array}$

676 atatgggcattagcaaagcgccttaataattggttgtgatata $\begin{array}{llllllllllllllllllllll}I & W & A & I & A & K & A & P & I & I & I & G & C & D & I\end{array}$

721 cgatccatggacgaaactaccaaagaatcctaagcaacaaaggg $\begin{array}{lllllllllllllllllll}R & S & M & D & E & T & T & K & E & I & L & S & N & K & G\end{array}$

766 gttttgcagttaaccaagataaacttggagttcaaggtaaaaa $\begin{array}{llllllllllllllllllll}V & F & A & V & N & Q & D & K & L & G & V & Q & G & K & K\end{array}$

811 gttaagagtgatagcggcttggaggtttgggccggaccactaagt 855

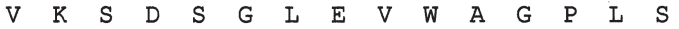
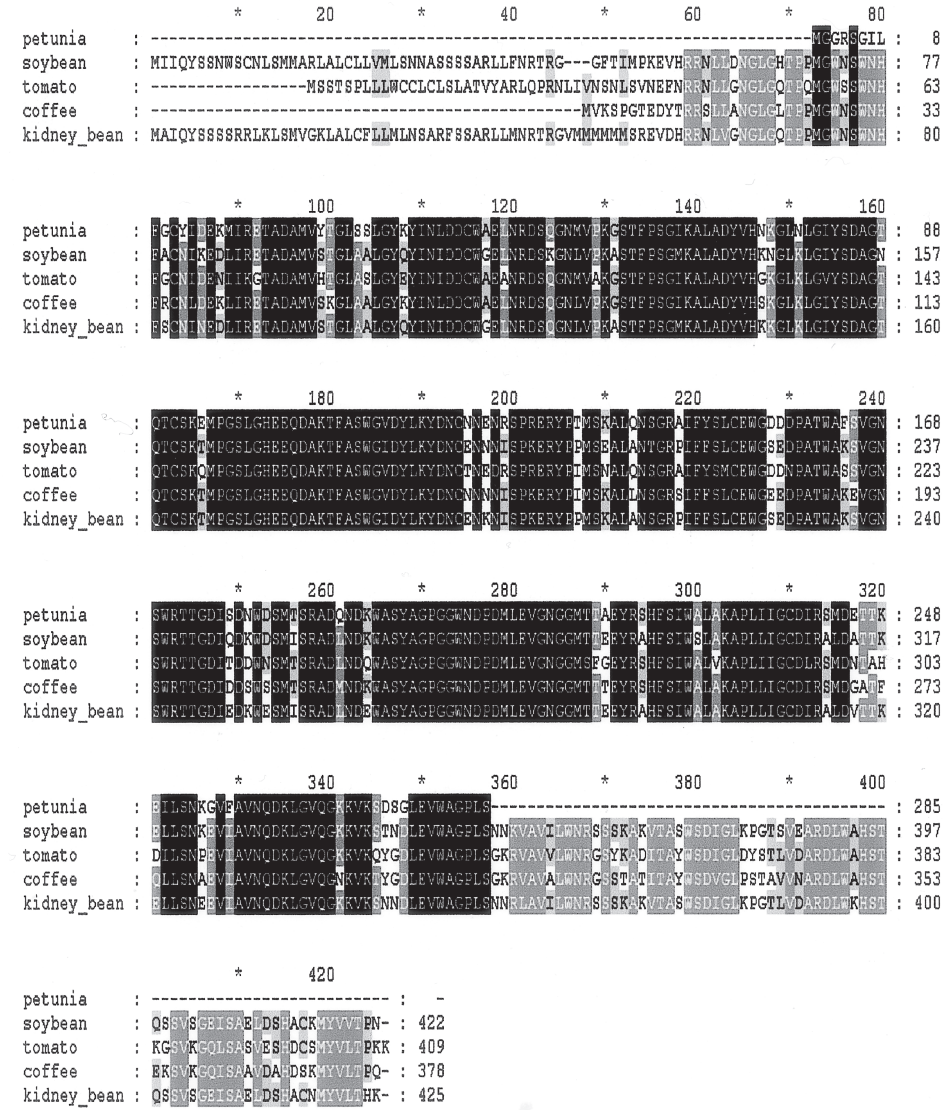

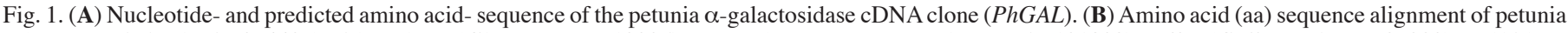
(Petunia $\times$ hybrida; AY374437) with soybean (Glycine max; U12926), tomato (Lycopersicon esculentum; AF191823), coffee (Coffee arabica; L27992), and kidney bean (Phaseolus vulgaris; U12927). The alignment was performed using the Vector NTI Suite software informax. Identical aa are shaded in black while aa with in the PhGAL sequence that are shaded gray represent conserved substitutions.

${ }^{\circ} \mathrm{C}$. Membranes were then hybridized for $20 \mathrm{~h}$ at $43{ }^{\circ} \mathrm{C}$ with $10^{6}$ $\mathrm{cpm} / \mathrm{mL}{ }^{32} \mathrm{P}$-labeled $P h G A L \mathrm{cDNA}$. Following hybridization, the membranes were washed at $50{ }^{\circ} \mathrm{C}$ in $2 \times \mathrm{SSC}$ and $0.1 \%$ SDS for $30 \mathrm{~min}$ and $0.2 \times \mathrm{SSC}$ and $0.1 \% \mathrm{SDS}$ for $15 \mathrm{~min}$. Fragments were visualized using a phosphoimager (Storm 840; Molecular Dynamics, Sunnyvale, Calif.).

Statistical Analyses. Five replications were used for each treatment and all experiments were repeated once. Data for the different parameters were analyzed by analysis of variance (ANOVA) and for mean differences using Tukey's Studentized comparison test using SAS (Cary, N.C.).

\section{Results}

Characterization OF a-galactosidase cDNA. A partial cDNA encoding a putative $\alpha$-gal $(P h G A L)$ was amplified as a single PCR product $855 \mathrm{bp}$ in length. The nucleotide sequence of the PhGAL clone contains an ORF of 285 amino acids (Fig. 1A). A comparison of the cDNA sequence to others in GenBank revealed homologies (between $42 \%$ to $88 \%$ ) with human, microbial, and plant $\alpha$-gal genes over the region for which we have sequenced. Based on the alignment of the petunia $\alpha$-gal with other known plant $\alpha$-gals, it appears that the protein is conserved among species (Fig. 1B). Table 1 shows the nucleotide and amino acid identities between petunia $\alpha$-gal and those from other species. Petunia (AY374437) and tomato seed (AF191823) $\alpha$-gal, both in
Table 1. Nucleotide and amino acid sequence homology between petunia $\alpha$-galactosidase (AY374437) and six other plant $\alpha$-galactosidases.

\begin{tabular}{lcc}
\hline Plant & \multicolumn{2}{c}{ Homology $\left(\%\right.$ identities $\left.^{2}\right)$} \\
\cline { 2 - 3 }$($ GenBank accession ID) & Nucleotide & Amino acid \\
\hline Tomato & 88 & 83 \\
$\begin{array}{l}\text { AF191823) } \\
\begin{array}{l}\text { (Lffee } \\
(\text { 27992) }\end{array}\end{array}$ & 85 & 83 \\
$\begin{array}{l}\text { Kidney bean } \\
(\text { U12927) }\end{array}$ & 84 & 81 \\
$\begin{array}{l}\text { Soybean } \\
\text { (U12926) }\end{array}$ & 83 & 80 \\
$\begin{array}{l}\text { Guar } \\
\text { (X14619) }\end{array}$ & 85 & 78 \\
$\begin{array}{l}\text { Arabidopsis } \\
(\text { AC067753) }\end{array}$ & 81 & 76 \\
\hline
\end{tabular}

zHighest homologies selected.

the Solanaceae family, share $\approx 88 \%$ nucleotide homology.

EXPRESSION OF $\alpha$-galactosidase. The PhGAL clone was used to probe northern blots prepared with RNA from a number of tissues, including flowers, leaves, stems, and roots. Leaves at four stages of development and leaves from cold acclimated and deacclimated plants were also included. Similar amounts of $\alpha$-gal transcripts were detected in leaves, stems and flowers and to a 
A

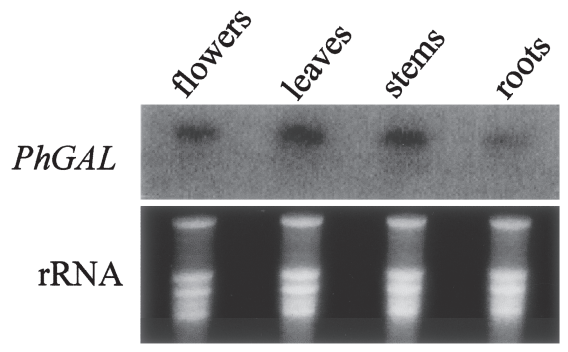

B

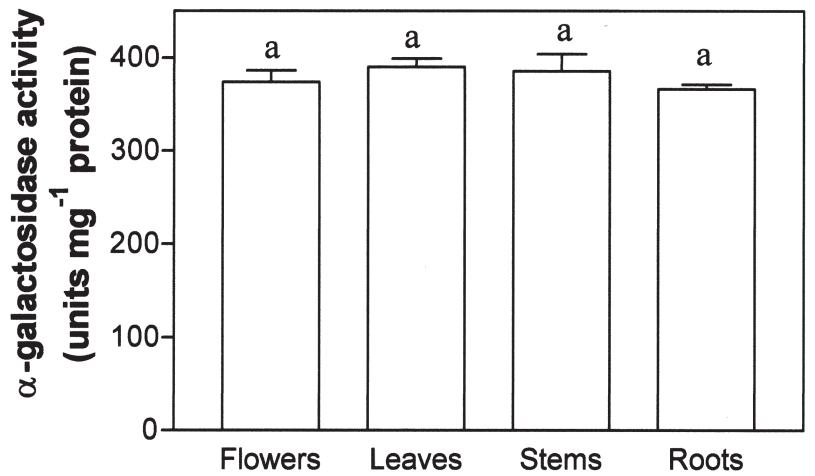

Fig. 2. Constitutive expression of PhGAL. (A) Northern blot analysis of total RNA isolated from various tissues of plants growing under normal conditions. Ten micrograms of total RNA were separated by electrophoresis through agarose and hybridized with $\alpha_{-3}{ }^{32}$ P-labeled PhGAL. Ribosomal RNA stained with ethidium bromide was used as a control to demonstrate equal loading of RNA. (B) $\alpha$-Galactosidase activity in various tissues. Error bars are standard deviation of five replications each from two separate experiments. Treatments with the same letter are not significantly different at $P<0.05$ by Tukey's Studentized comparison test (SAS).

slightly lesser degree in roots (Fig. 2A). Petunia $\alpha$-gal activity was the same in all tissues tested (ranging from $366.2 \pm 4$ to 389.8 $\pm 9 \mathrm{U} / \mathrm{mg}$ protein $)(p<0.05)$ (Fig. 2B). Petunia plants grown for 4 weeks had eight or more leaves (Fig. 3A). There was a clear growth gradient, with younger leaves growing faster than older leaves (Fig. 3B). The activity of $\alpha$-gal was not related to growth rate (Fig. $3 \mathrm{C}$ ) and neither was mRNA transcript acccumulation (Fig. 3D). RNA from leaves at varying developmental stages revealed a constitutive expression of $P h G A L$.

To analyze the regulation of gene expression by temperature, mRNA transcripts were monitored following cold acclimation and following deacclimation at $25^{\circ} \mathrm{C}$ for $30,60,75,90,120$, and 180 min (Fig. 4A). PhGAL mRNA was detected throughout the time course, but transcript abundance increased 60 min into deacclimation. Transcript abundance of $P h G A L$ remained relatively constant through $90 \mathrm{~min}$, but mRNA accumulation decreased to control amounts by $120 \mathrm{~min}$. A similar trend was observed for $\alpha$ gal activity with a sharp rise in activity 60 min into deacclimation (Fig. 4B). Raffinose content decreased significantly $60 \mathrm{~min}$ into deacclimation after which raffinose amounts remained constant for up to $180 \min (P<0.05)$ (Fig. 4B). Membrane leakage of nonchilled and cold-acclimated chilled plants was significantly lower than that of deacclimated chilled plants (Fig. 4C). Petunia deacclimated after only $1 \mathrm{~h}$ of exposure to $25^{\circ} \mathrm{C}$ as indicated by electrolyte leakage tests. To learn how deacclimating temperatures other than $25^{\circ} \mathrm{C}$ affected $P h G A L$ expression, a temperature doseresponse experiment was performed. Total RNA was isolated from petunia plants deacclimated for $60 \mathrm{~min}$ at $25,30,35$, or 40 ${ }^{\circ} \mathrm{C}$. Although all treatments induced $P h G A L$ transcripts, deac- climation at $30{ }^{\circ} \mathrm{C}$ resulted in the greatest mRNA accumulation (Fig. 5A). At $35{ }^{\circ} \mathrm{C}$ deacclimation, transcript levels decreased, but at $40{ }^{\circ} \mathrm{C}$ transcripts were barely detectable. $\alpha$-Galactosidase activity followed a similar trend (Fig. 5B).

\section{Discussion}

It has long been shown that RFOs, particularly the trisaccharide raffinose, may play a role in the acquisition of cold tolerance in plants(Guy 1990). The opposite process, i.e., deacclimation whereby

$\mathbf{A}$

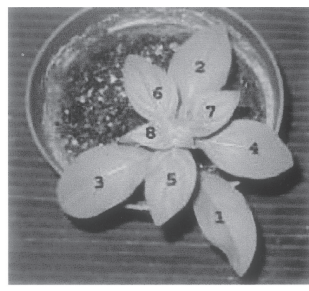

B

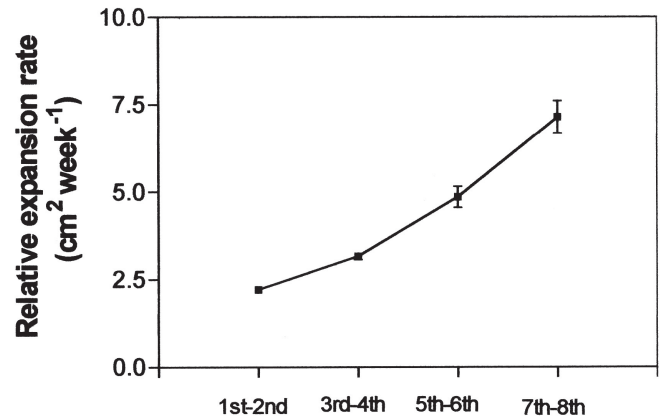

$\mathbf{C}$

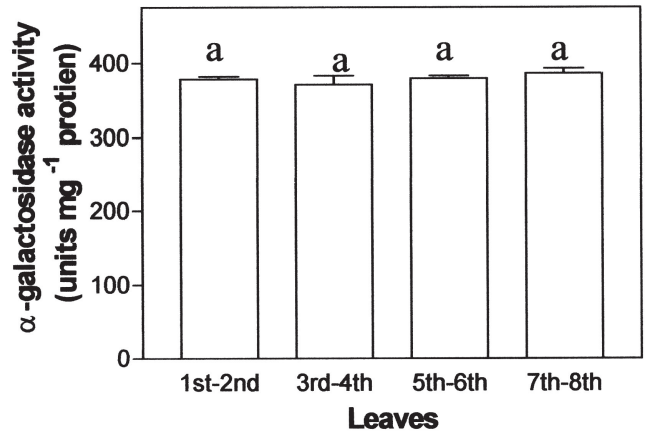

D

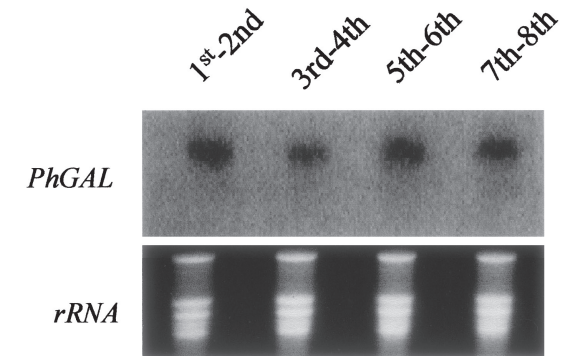

Fig. 3. Nondevelopmental regulation of PhGAL. (A) Petunia plant showing the first eight true leaves numbered according to their appearance order. (B) Leaf relative expansion rate as a function of developmental stage. Leaves were classified in four groups. (C) $\alpha$-Galactosidase activity in the four leaf groups. (D) Northern blot analysis of the four leaf groups. Ribosomal RNA stained with ethidium bromide was used as a control to demonstrate equal loading of RNA. Error bars are standard deviation of five replications each for two separate experiments. Treatments with the same letter are not significantly different at $P<0.05$ by Tukey's Studentized comparison test (SAS). 
RFOs are catabolized, has not been as extensively studied, and therefore forms the basis of our study. In an attempt to understand the function of $\alpha$-gal during deacclimation, a partial length cDNA clone encoding a putative $\alpha$-galactosidase was isolated and its mRNA expression was characterized.

Alignment of the petunia $\alpha$-gal enzyme with other plant $\alpha$-gals shows that the protein is conserved among species. Comparison of the nucleotide and the deduced amino acid sequences of the PhGAL clone revealed a considerable degree of homology to known plant $\alpha$-gals. In contrast, comparison of the protein sequences of two alkaline $\alpha$-gals from melon showed practically no homology to other known plant $\alpha$-gals (Cami et al., 2003). The plant alkaline $\alpha$-gals appear to be phytogenetically distinct from the family 27 eukaryotic $\alpha$-gals, most of which are acidic $\alpha$-gals (Cami et al., 2003). The $\mathrm{pH}$ optimum for $\alpha$-gal activity of total protein extracts from petunia leaves was pH 6.0 (data not shown). However PhGAL has not been purified, and therefore it is not known whether PhGAL may be classified as an acidic $\alpha$-gal. Although all the $\alpha$-gals cata-

\section{Deacclimation (min)}

$\mathbf{A}$

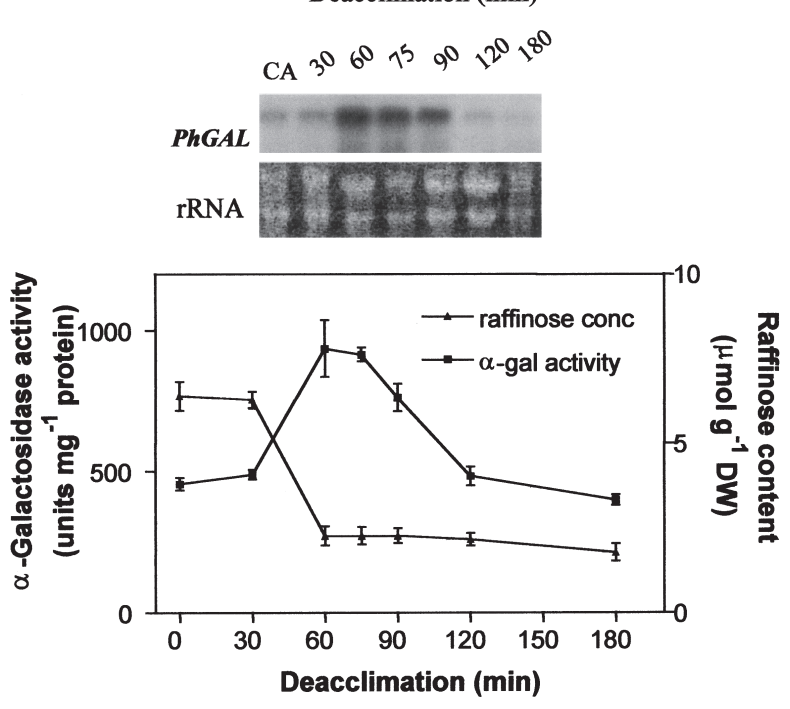

C

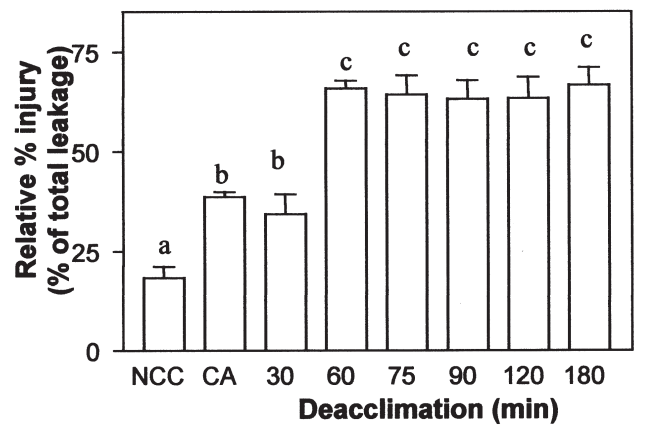

Fig. 4. Deacclimation-induced expression of $P h G A L$ in petunia. (A) Northern blot analysis of petunia plants cold acclimated (CA) at $15^{\circ} \mathrm{C}$ for $7 \mathrm{~d}, 10^{\circ} \mathrm{C}$ for $7 \mathrm{~d}, 5^{\circ} \mathrm{C}$ for $7 \mathrm{~d}$, and subsequently $3^{\circ} \mathrm{C}$ for $3 \mathrm{~d}$ and deacclimated at 25 ${ }^{\circ} \mathrm{C}$ for the indicated lengths of time. Each lane was loaded with $10 \mu \mathrm{g}$ total RNA. Ribosomal RNA stained with ethidium bromide was used as a control to demonstrate equal loading. (B) Relationship of $\alpha$-gal activity and raffinose content in response to deacclimation. Cold acclimated plants ( $0 \mathrm{~h}$ deacclimation) were deacclimated by incubating at $25^{\circ} \mathrm{C}$ and sampled at various times for $\alpha$-gal activity and raffinose content using HPLC. C. CI evaluated by electrolyte leakage as a measure of deacclimation. Samples were collected from nonchilled control (NCC) plants and from chilled plants $\left(2{ }^{\circ} \mathrm{C}\right.$ for $\left.1 \mathrm{~h}\right)$ following CA and deacclimation at $25^{\circ} \mathrm{C}$ for the indicated lengths of time. Error bars are standard deviation of five replications each for two separate experiments. Treatments with the same letter are not significantly different at $P<0.05$ by Tukey's Studentized comparison test (SAS). lyze the same reaction, i.e., splitting $\alpha$-linked galactose moieties, their $\mathrm{pH}$ profile, amino acid composition, enzyme kinetics, and cellular location may differ (Overbeeke et al., 1989). It is also not uncommon for some plants to have more than one isoform of the enzyme. Despite these differences, two conserved domains have been identified among the three $\alpha$-gal families (i.e., family 27 eukaryotic, family 36 prokaryotic, and plant alkaline $\alpha$-gals/SIPs) suggesting a similar catalytic mechanism (Cami et al., 2003). These domains are also conserved in the PhGAL predicted amino acid sequence (DomainADD $\times W$ found at petunia amino acid $41-44$ and DomainB K $\times$ D found at petunia amino acid 118-120). Site-directed mutagenesis studies in coffee bean have demonstrated that Tyr-108 is critical for $\alpha$-gal activity (Zhu et al., 1995), and this Tyr residue (Tyr-83) is also conserved in petunia providing further evidence that $P h G A L$ encodes an $\alpha$-gal.

Southern hybridization using $P h G A L$ as a probe suggests that the $\alpha$-gal represents a single gene in petunia (data not shown). Similarly, only one gene is reported for tomato seed $\alpha$-gal (Feurtado et al., 2001) while two different $\alpha$-gal genes are reported for barley (Chrost and Krupinska, 2000) and four in Arabidopsis (TAIR website: http://www.arabidopsis.org/).

The presence of the enzyme in different plant tissues suggests that $\alpha$-gal is not only involved in raffinose degradation but plays a broader role in galactomannan remobilization during seed germination (Feurtado et al., 2001). In plants not synthesizing these oligosaccharides, $\alpha$-gal seems to be involved in galactolipid metabolism of plastid membranes (Chrost and Krupinska, 2000). $\alpha$-Galactosidase

A

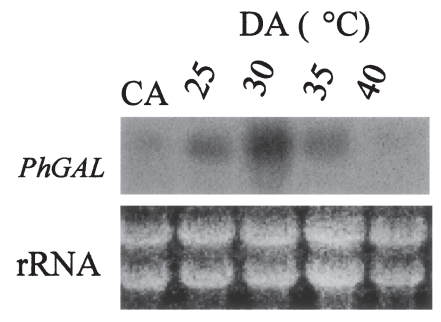

B

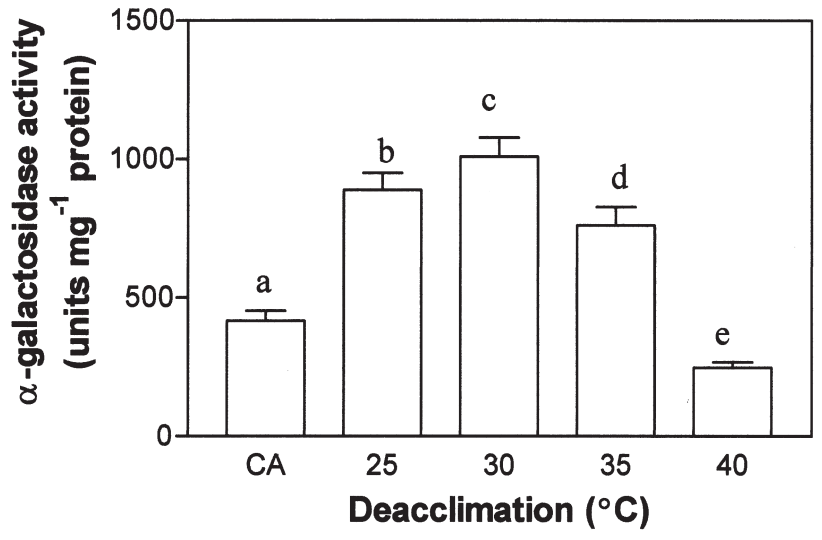

Fig. 5. Temperature dose response of PhGAL. (A) Northern blot analysis of petunia plants cold acclimated $(\mathrm{CA})$ at $15^{\circ} \mathrm{C}$ for $7 \mathrm{~d}, 10^{\circ} \mathrm{C}$ for $7 \mathrm{~d}, 5^{\circ} \mathrm{C}$ for $7 \mathrm{~d}$, and subsequently $3^{\circ} \mathrm{C}$ for $3 \mathrm{~d}$ and deacclimated (DA) for $1 \mathrm{~h}$ at the indicated temperatures. Each lane was loaded with $10 \mu \mathrm{g}$ total RNA, separated by electrophoresis through agarose and hybridized with $\alpha-{ }^{32} \mathrm{P}$-labeled PhGAL. Ribosomal RNA stained with ethidium bromide was used as a control to demonstrate equal loading of RNA. (B) $\alpha$-Galactosidase activity in petunia plants following cold acclimation (CA) and deacclimation for $60 \mathrm{~min}$ at various temperatures. Error bars are standard deviation of five replications each for two separate experiments. Treatments with the same letter are not significantly different at $p<0.05$ by Tukey's studentized comparison test (SAS). 
activity and transcript accumulation were detected in all of the tissues tested suggesting that $P h G A L$ is not tissue specific but rather is involved in nonspecific degradation of raffinose. In tomato for example, EST clones were isolated from seed (GenBank accession numberAF191823), ovary (GenBank accession numberAI898528) and root (GenBank accession number BE451601).

$P h G A L$ is not developmentally regulated, as its pattern of transcript accumulation is unchanged throughout plant development. Consistent with our findings, is the observation that $\alpha$-gal activity in cucurbit leaves remained constant at all stages of development (Thomas and Webb, 1978). In contrast, the activity of stachyose synthase, an RFO biosynthetic enzyme donating a second galactosyl moiety to raffinose, can change dramatically in response to plant developmental stage and leaf age (Holthaus and Schmitz, 1991). The cucurbits translocate RFO predominantly, hence the biosynthetic enzymes (galactinol synthase, raffinose synthase, stachyose synthase) are expected to be upregulated in mature leaves (source tissues). $\alpha$-Galactosidase is therefore expected to be upregulated in young leaves (sink tissues) to degrade RFO into sucrose and galactose. Since petunia translocates sucrose primarily (data not shown), large quantities of $\alpha$-gal are not necessary for RFO degradation. This observation is consistent with constant levels of $\alpha$-gal activity in petunia observed throughout leaf development.

The most interesting finding in this study is the rapid activation of $P h G A L$ with the onset of deacclimation. The observed changes in mRNA abundance and $\alpha$-gal activity are likely to be involved in the metabolic changes that occur during loss of hardiness. $\alpha$ Galactosidase responded to $25^{\circ} \mathrm{C}$ (deacclimation) with increased activity and with a concomitant decrease in raffinose content, suggesting a regulatory role of $\alpha$-gal in raffinose catabolism. This increased activity may be due to gene activation and as such the $\alpha$-gal gene may provide a genetic target for manipulating cold hardiness in plants. Most of the published work on RFO and stress tolerance were related to their role in the acquisition of tolerance to extensive desiccation and freezing tolerance. There is comparatively little suggestive evidence regarding their role in low, nonfreezing temperatures. Induction of $\alpha$-gal mRNA corresponding to $P h G A L$ was detected in acclimated plants subjected to deacclimation at 25 or $30^{\circ} \mathrm{C}$. Transcript levels rapidly decreased when the temperature was increased from 35 to $40^{\circ} \mathrm{C}$, approximately the threshold temperature for heat-induced damage of petunia. The comprehensive analysis of $P h G A L$ expression in this study suggests that this gene can be added to the large and growing list of genes regulating cold hardiness, in this case, loss of hardiness. Gene expression was not tissue-specific and was without developmental regulation although rapid expression occurred in response to increased temperature. The data revealed that the single gene shows distinct expression patterns upon temperature treatments, allowing predictions of when its function is expected to become physiologically important. Furthermore, petunia deacclimates after only 60 min of exposure to high temperature and while this has obvious implications during the inclement fall weather, altering this response could be valuable for the improvement of ornamentals in the landscape. This information has potential practical implications whereby $\alpha$-gal may be targeted to modify endogenous raffinose accumulation in tissues needed for freezing stress tolerance. As such, the growing season of low temperature sensitive species could be extended, permitting earlier spring plantings and later growth during fall when frost injury is most likely.

\section{Literature Cited}

Altschul, S.F., T.L. Madden, A.A. Schaffer, J. Zhang, Z. Zhang, W. Miller, and D.J. Lipman. 1997. Gapped BLAST and PSI-BLAST: A new generation of protein database search programs. Nucleic Acids Res. 25:3389-3402.

Bachmann, M., P. Matile, and F. Keller. 1994. Metabolism of the raffinose family oligosaccharides in leaves of Ajuga reptans L. Cold acclimation, translocation and sink to source transition: Discovery of chain elongation enzyme. Plant Physiol. 105:1335-1345.

Bishop, D.F., D.H. Calhoun, H.S. Bernstein, P. Hantzopoulos, M. Quinn, and R.J.Desnick. 1986. Human $\alpha$-galactosidase A: Nucleotide sequence of a cDNA clone encoding the mature enzyme. Proc. Natl. Acad. Sci. USA 83:4859-4863.

Cami, N., G. Zhang, M. Petreikov, Z. Gao, Y. Eyai, D. Granot, and A.A. Schaffer. 2003. Cloning and functional expression of alkaline $\alpha$-galactosidase from melon fruit: Similarity to plant SIP proteins uncovers a novel family of plant glycosyl hydrolases. The Plant J. 33:97-106.

Castonguay, Y. and P. Nadeau. 1998. Crop physiology and metabolism: Enzymatic control of soluble carbohydrate accumulation in cold acclimated crowns of alfalfa. Crop. Sci. 38:1183-1189.

Chrost, B. and K. Krupinska. 2000. Genes with homologies to known $\alpha$-galactosidases are expressed during senescence of barley leaves. Physiol. Plantarum 110:111-119.

Davis, M.O., D.J. Hata, S.A. Johnson, J.C. Walker, and D.S. Smith. 1996. Cloning, expression and characterization of a blood group B active recombinant $\alpha$-galactosidase from soybean (Glycine max). Biochem. Mol. Biol. Intl. 39:471.

Denhardt, D.T. 1966. A membrane-filter technique for the detection of complementary DNA. Biochem. Biophys. Res. Commun. 23:641-646.

Feurtado, J.A., M. Banik, and J.D. Bewley. 2001. The cloning and characterization of $\alpha$-galactosidase present during and following germination of tomato (Lycopersicon esculentum Mill.) seed. J. Expt. Bot. 52:1239-1249.

Gao, Z. and A.A. Schaffer. 1999. A novel alkaline alpha-galactosidase from melon fruit with a substrate preference for raffinose. Plant. Physiol. 119:979-987.

Gaudreault, P.R. and J.A. Webb. 1986. Alkaline $\alpha$-galactosidase activity and galactose metabolism in the family cucurbitaceae. Plant Sci. 45:71-75.

Guy, C.L. 1990. Cold acclimation and freezing stress tolerance: Role of protein metabolism. Annu. Rev. Plant Physiol. Plant Mol. Biol. 41:187-223.

Holthaus, U. and K. Schmitz. 1991. Distribution and immunolocalization of stachyose synthase in Cucumis melo L. Planta 185:479-486.

Keller, F. and D.M. Pharr. 1996. Metabolism of carbohydrates in sink and sources: Galactosyl-sucrose oligosaccharides, p. 157-183. In: E. Zamski (ed.). Crops. Marcel Dekker, New York.

Liljestrom, P.L. 1985. The nucleotide sequence of the yeast MEL1 gene. Nucleic Acids Res. 13:7257-7268.

Lowry, H., N. Rosebrough, A. Fan, and R. Randall. 1951. Protein measurement with the Folin phenol reagent. J. Biol. Chem. 193:265-275.

McIlvaine, T.C. 1921. A buffer solution for colorimetric comparison. J. Biol. Chem. 49:183-186.

Overbeeke, N., A.J. Fellinger, M.Y. Toonen, D. van Wassenaar, and C.T. Verrips. 1989. Cloning and nucleotide sequence of the $\alpha$-galactosidase cDNA from Cyamopsis tetragonoloba (guar). Plant Mol. Biol. 13:541-550.

Smart, E.L. and D.M. Pharr. 1980. Characterization of $\alpha$-Galactosidase from cucumber leaves. Plant Physiol. 66:731-734.

Stushnoff, C., M.J. Seufferheld, and T. Creegan. 1998. Oligosaccharides as endogenous cryoprotectants in woody plants, p. 301-309. In: P.H. Li and T.H.H. Chen (eds.). Plant cold hardiness: Molecular biology, biochemistry and physiology. Plenum Press, New York.

Taji, T., C. Ohsumi, S. Iuchi, M. Seki, M. Kasuga, M. Kobayashi, K. Yamaguchi-Shinozaki, and K. Shinozaki. 2002. Important roles of drought- and cold-inducible genes for galactinol synthase in stress tolerance in Arabidopsis thaliana. The Plant J. 29:417-426.

Thomas, B. and J.A. Webb. 1978. Distribution of $\alpha$-galactosidase in Cucurbita pepo. Plant Physiol. 62:713-717.

Zhu, A. and J. Goldstein. 1994. Cloning and functional expression of DNA encoding coffee bean $\alpha$-galactosidase. Gene 140:227-231.

Zhu, A., Z.K. Wang, and J. Goldstein. 1995. Identification of Tyrosine-108 in coffee bean alpha-galactosidase as an essential residue for enzyme activity. Biochim. Biophys. Acta 1247:260-264. 